\title{
Diagnostic effectiveness of soluble triggering receptor expressed on myeloid cells-1 in sepsis, severe sepsis and septic shock
}

Monika Jedynak, Andrzej Siemiatkowski, Robert Milewski, Barbara Mroczko, Maciej Szmitkowski

Department of Anaesthesiology and Intensive Therapy, Medical University of Bialystok, Bialystok, Poland

Submitted: 14 November 2016

Accepted: 20 March 2017

Arch Med Sci 2019; 15 (3): 713-721

DOI: https://doi.org/10.5114/aoms.2018.73090

Copyright @ 2019 Termedia \& Banach

\section{Abstract}

Introduction: Sensitivities and specificities of clinical signs and biochemical tests in sepsis diagnosis are not satisfactory. The aim of the study was to assess the diagnostic usefulness of soluble triggering receptor expressed on myeloid cells-1 (sTREM-1) in sepsis, severe sepsis and septic shock against interleukin-6 (IL-6), C-reactive protein (CRP) and procalcitonin (PCT).

Material and methods: A prospective, observational study was conducted in 85 adults with sepsis, severe sepsis or septic shock and 22 with non-infective systemic inflammatory response syndrome (NI-SIRS). Serum levels of STREM-1, CRP, PCT and IL- 6 were measured on admission.

Results: Median serum STREM-1 concentrations were higher in severe sepsis $(540 \mathrm{pg} / \mathrm{ml})$ and septic shock $(536 \mathrm{pg} / \mathrm{ml})$ in comparison with NI-SIRS patients $(p<0.05)$. There were no differences in sTREM- 1 levels between NI-SIRS and sepsis. Similarly, CRP, PCT and IL- 6 were significantly elevated in patients with severe sepsis and septic shock in comparison with NI-SIRS. The receiver operating characteristic curve analysis for diagnosis of severe sepsis showed higher discriminative value for CRP and IL-6 (AUC $=0.909$, $95 \% \mathrm{Cl}: 0.829-0.99$ and $\mathrm{AUC}=0.854,95 \% \mathrm{Cl}: 0.728-0.980$, respectively) than sTREM-1 ( $\mathrm{AUC}=0.733,95 \% \mathrm{Cl}: 0.596-0.870)$. In septic shock the highest AUC was found for CRP (AUC $=0.938,95 \% \mathrm{Cl}$ : $0.872-1.0$ ), lower for IL-6 $(A \cup C=0.869,95 \% \mathrm{Cl}: 0.751-0.987)$, PCT $(A \cup C=0.828,95 \% \mathrm{Cl}: 0.71-0.945)$ and STREM-1 (AUC $=0.705,95 \% \mathrm{Cl}: 0.553-0.856$ ).

Conclusions: Serum level of STREM-1 has lower effectiveness as a diagnostic biomarker in severe sepsis and septic shock, in comparison with CRP and IL-6.

Key words: diagnosis, infection, mediators, inflammation.

\section{Introduction}

Despite the huge improvement in clinical management of sepsis, its severe forms are the leading cause of mortality in intensive care units (ICU) $[1,2]$. The introduction of proper treatment requires early differentiation between infective and non-infective systemic inflammatory response syndrome (SIRS) and the localization of the injury or infection. Because there is a common inflammatory pathway for infection and injury, it is very difficult to find a biomarker specific for an infection. Many scientific studies are being conducted in order to find a mediator with high diagnostic accuracy in the early stages of sepsis.

\author{
Corresponding author: \\ Dr. Monika Jedynak \\ Department of \\ Anaesthesiology \\ and Intensive Therapy \\ Medical University \\ of Bialystok \\ 24 A M. Sklodowskiej-Curie St \\ 15-276 Bialystok, Poland \\ Phone: +48601503 395 \\ E-mail: monika.jedynak@ \\ umb.edu.pl
}


One promising biomarker is triggering receptor expressed on myeloid cells-1 (TREM-1), an approximately $30 \mathrm{kDa}$ glycoprotein which belongs to the immunoglobulin superfamily. This transmembrane molecule is expressed in the late stages of myeloid cell maturation, on neutrophils, monocytes and macrophages. In response to infection, pathogens and their components such as lipopolysaccharide are recognized by toll-like receptor 2 or 4 and enhanced TREM-1 expression. This results in release of inflammatory cytokines and increased expression of other receptors on the surface of inflammatory cells [3]. Activated macrophages and monocytes secrete high-mobility group box 1 protein, which is responsible for maintaining proper structure of the cell nucleus and for gene transcription processes [4]. Extracellular domain of TREM-1 was identified in human body fluids of infected patients as the soluble form (sTREM-1) and it was demonstrated to inhibit its cellular form [5]. The expression of TREM-1 increased in bacterial and fungal infections and an elevated level of the soluble form was proposed to be indicative of an infection in sepsis $[6,7]$, pneumonia and meningitis $[8,9]$.

Sensitivities and specificities of clinical signs of sepsis and commonly used laboratory tests are not satisfactory in sepsis diagnosis and do not allow us to use them individually. Procalcitonin (PCT), C-reactive protein (CRP) and interleukin-6 (IL-6) were found to be very helpful in diagnosis of sepsis in its severe forms and they are commonly used in clinical practice $[10,11]$. Although they facilitate differentiation between sepsis and NISIRS, their accuracies are not sufficient. In recent clinical studies, serum concentrations of STREM-1 were found to be promising in diagnosis of sepsis. However, detailed results of different researchers are inconsistent.

The aim of the present study was to evaluate the diagnostic usefulness of serum STREM-1 level in sepsis, severe sepsis and septic shock against other commonly used biomarkers such as IL-6, CRP and PCT.

\section{Material and methods}

This prospective observational study was performed from March 2010 to February 2013 in a ten-bed mixed adults ICU at the Department of Anesthesiology and Intensive Therapy, Medical University Hospital. Patients admitted to the ICU were evaluated within $12 \mathrm{~h}$ for SIRS and then divided into sepsis, severe sepsis, septic shock or NI-SIRS, according to the present guidelines [12, 13]. For some analyses patients with sepsis, severe sepsis and septic shock were combined into a systemic infection (SI) group. The healthy control $(\mathrm{HC})$ group comprised healthy volunteers from medical staff and students, who were asked to participate. The Medical University of Bialystok Ethical Committee on research on humans and animals approved this study. Written informed consent was obtained from patients or relatives. Exclusion criteria included age below 18 years old, disseminated malignant disease, pregnancy, AIDS or immunosuppressive treatment and life expectancy shorter than $24 \mathrm{~h}$. The observation was continued until death or discharge from the hospital.

Data recorded age, gender, principal diagnosis, admission category, mortality, the length of mechanical ventilation and ICU stay, acute physiology and chronic health evaluation II (APACHE II) score, simplified acute physiology score II (SAPS II), sequential organ failure assessment (SOFA) score, routine blood tests and microbiological culture results. Arterial blood was drawn at the time of initial laboratory evaluation for sepsis, centrifuged, and sera were stored at $-70^{\circ} \mathrm{C}$ until analysis. Serum STREM- 1 and IL- 6 were measured twice in each sample with enzyme-linked immunosorbent assays with a lower detection limit of $3.88 \mathrm{pg} / \mathrm{ml}$ and $0.7 \mathrm{pg} / \mathrm{ml}$, respectively (Human TREM-1 Quantikine ELISA Kit, Human IL-6 Quantikine ELISA Kit; R\&D Systems, Minneapolis, USA), according to the manufacturer's instructions. The intra-assay CV for STREM-1 is claimed by the manufacturer of assay kits to be $4.2 \%$ at a mean STREM- 1 concentration of $1212 \mathrm{pg} / \mathrm{ml}$. The intra-assay CV for IL-6 is claimed by the manufacturer of assay kits to $1.6 \%$ at a mean IL-6 concentration of $97.7 \mathrm{pg} /$ $\mathrm{ml}$. The PCT was analyzed by an enzyme-linked fluorescent immunoassay (ELFA) for the quantitative measurement with measuring range from $0.05 \mathrm{ng} / \mathrm{ml}$ to $200 \mathrm{ng} / \mathrm{ml}(\mathrm{VIDAS} \mathrm{B} \cdot \mathrm{R} \cdot \mathrm{A} \cdot \mathrm{H} \cdot \mathrm{M} \cdot \mathrm{S}$ PCT bioMérieux, France). The intra-assay CV for PCT is claimed by the manufacturer of the assay kits to be $2.08 \%$ at a mean PCT concentration of $1.91 \mathrm{ng} /$ $\mathrm{ml}$. The level of CRP in serum was determined by the latex immunoassay Multigent CRP Vario Standard Method (Abbott Laboratories Inc. USA and ABBOTT, Wiesbaden, Germany). The reportable range for CRP Vario is $0.2 \mathrm{mg} / \mathrm{l}$ to $320 \mathrm{mg} / \mathrm{l}$. The intra-assay CV for CRP is claimed by the manufacturer of assay kits to be $0.72 \%$ at a mean CRP concentration of $4.92 \mathrm{mg} / \mathrm{l}$.

\section{Statistical analysis}

Since the data were not normally distributed, the results are presented as medians and interquartile ranges. For comparison between the two groups, the non-parametric Mann-Whitney $U$ test was used and ANOVA rank Kruskal-Wallis oneway analysis of variance by ranks with post-hoc analysis for more than two groups. Results for qualitative variables were denoted as percentages and compared across groups by means of the 
$\chi^{2}$ test. Receiver operating characteristic (ROC) curves were constructed considering NI-SIRS versus $\mathrm{SI}$ and versus sepsis, severe sepsis and septic shock independently. The diagnostic ability of STREM-1, CRP, PCT and IL- 6 was expressed as the area under the ROC curve (AUC). Youden's index was used to choose the best cut-off points for assessment of sensitivity, specificity and predictive values. $P<0.05$ was considered statistically significant. Statistical analysis was performed using Statistica 10.0 for Windows.

\section{Results}

\section{Patients' characteristics}

A total of 107 adult ICU patients meeting criteria for SIRS were prospectively included in the study. Eighty-five patients with SI were divided into three groups: 29 with sepsis, 32 with severe sepsis and 24 with septic shock. The remaining 22 cases were diagnosed as NI-SIRS: 12 with trauma injury, 6 with hypovolemic shock, 2 with cardiogenic shock and 2 with postoperative SIRS. Thirty healthy volunteers comprised the $\mathrm{HC}$ group, including 11 (37\%) men and 19 (64\%) women with median age of 22, ranging from 20 to 31 . Contrary to NI-SIRS, sepsis and severe sepsis, there were more women than men in the septic shock group $(p<0.01)$. The frequency of medical admission did not differ significantly between groups. Forty-five (53\%) and 25 (29\%) patients had pulmonary and abdominal infection, respectively. The most frequent cause of systemic infection was Gram-negative bacteria (48\%). The 28-day mortality rates,
SAPS || and APACHE || scores did not differ between groups. Patients with SI had longer time of artificial ventilation and time of ICU treatment, higher SOFA score and rate of four or more organs failure than NI-SIRS cases $(p<0.001)$ (Table I).

\section{sTREM-1, CRP, PCT and IL-6 in SI and NI-SIRS}

On admission, median serum levels of sTREM-1 (503 pg/ml), CRP (145 mg/l), РCT (2.2 ng/ml) and IL-6 (247.5 pg/ml) were significantly elevated in $\mathrm{SI}$ patients in comparison with the $\mathrm{HC}$ group $(120 \mathrm{pg} / \mathrm{ml}, p<0.001 ; 0.55 \mathrm{mg} / \mathrm{l}, p<0.01 ; 0.05 \mathrm{ng} /$ $\mathrm{ml}, p<0.001 ; 0.79 \mathrm{pg} / \mathrm{ml}, p<0.01$; respectively). Similarly, NI-SIRS patients presented higher levels of sTREM-1 (350 pg/ml), CRP (46.6 mg/l), PCT $(1.47 \mathrm{ng} / \mathrm{ml})$ and IL-6 $(25.5 \mathrm{pg} / \mathrm{ml})$ than healthy controls ( $p<0.01$ for all).

There were no significant differences in the concentrations of STREM-1 between patients with SI and NI-SIRS $(p=0.06)$. Contrary to this, serum CRP, PCT and IL- 6 levels were significantly elevated in SI patients in comparison with NI-SIRS (145 mg/l vs. $46.6 \mathrm{mg} / \mathrm{l}, p<0.001 ; 2.2 \mathrm{ng} / \mathrm{ml}$ vs. $1.47 \mathrm{ng} / \mathrm{ml}, p<0.05 ; 247.5 \mathrm{pg} / \mathrm{ml}$ vs. $25.5 \mathrm{pg} / \mathrm{ml}$, $p<0.001$, respectively).

\section{STREM-1, CRP, PCT and IL-6 in sepsis, severe sepsis and septic shock}

The analysis of patients with sepsis, severe sepsis and septic shock separately showed that median STREM-1 level in sepsis $(350 \mathrm{pg} / \mathrm{ml})$ and $\mathrm{NI-SIRS} \mathrm{(367} \mathrm{pg/ml)} \mathrm{did} \mathrm{not} \mathrm{differ,} \mathrm{but} \mathrm{it} \mathrm{increased}$ significantly in severe sepsis to $540 \mathrm{pg} / \mathrm{ml}$

Table I. Patient characteristics and demographic data

\begin{tabular}{|c|c|c|c|c|c|}
\hline Characteristic & $\begin{array}{l}\text { NI-SIRS } \\
(n=22)\end{array}$ & $\begin{array}{l}\text { Sepsis } \\
(n=29)\end{array}$ & $\begin{array}{l}\text { Severe sepsis } \\
\quad(n=32)\end{array}$ & $\begin{array}{l}\text { Septic shock } \\
\quad(n=24)\end{array}$ & $\begin{array}{c}\text { SI } \\
(n=85)\end{array}$ \\
\hline Age [years] & $60(37-75)$ & $68(39-75)$ & $72(61.5-65.5)$ & $62(53.5-74.5)$ & $68(55-75)$ \\
\hline Male/female & $20 / 2$ & $21 / 8$ & $23 / 9$ & $10 / 14$ & $54 / 31^{\star *}$ \\
\hline Days of ICU stay & $8.5(6-15)$ & $18(8-23)$ & $14(7-26)$ & $16(10.5-55)$ & $16^{* *}(8-27)$ \\
\hline Days of ventilation & $6.5(2-11)$ & $12(5-21)$ & $11(5.5-26)$ & $11(8-50.5)$ & $11^{\star *}(7-25)$ \\
\hline SAPS II score & $36(26-56)$ & $36(31-45)$ & $41(36-47.5)$ & $48(36-60)$ & $40(34-53)$ \\
\hline APACHE II score & $13(9-20)$ & $14(11-17)$ & $17(13.5-21)$ & $19(15-24)$ & $16(13-21)$ \\
\hline SOFA score & $7.5(6-9)$ & $7(5-9)$ & $9(6.5-10)$ & $10(8-12)$ & $9^{*}(6-11)$ \\
\hline $\begin{array}{l}\text { Failure of } 4 \text { or more } \\
\text { organs }\end{array}$ & $9(41 \%)$ & $16(55 \%)$ & $21(66 \%)$ & $17(71 \%)$ & $54^{\star}(63.5 \%)$ \\
\hline 28-day MR & $5(22.7 \%)$ & $3(10.3 \%)$ & $6(18.8 \%)$ & $5(20.8 \%)$ & $14(16.5 \%)$ \\
\hline 3-month MR & $6(27 \%)$ & $12(41.4 \%)$ & $14(44 \%)$ & $9(37.5 \%)$ & $35(41 \%)$ \\
\hline Medical admission & $10(45.5 \%)$ & $20(69 \%)$ & $20(62.5 \%)$ & $15(62.5 \%)$ & $55(65 \%)$ \\
\hline
\end{tabular}

Quantitative data of non-normal distribution are presented as median and interquartile range. Qualitative data are presented as number (percentage). NI-SIRS - non-infective systemic inflammatory response syndrome, SI - systemic infection, ICU - intensive care unit, SAPS II - Simplified Acute Physiology II, APACHE II - Acute Physiology and Chronic Health Evaluation II, SOFA - The Sequential Organ Failure Assessment, MR - mortality rate. ${ }^{*} p<0.05,{ }^{* *} p<0.01,{ }^{* * *} p<0.01$ versus NI-SIRS. 


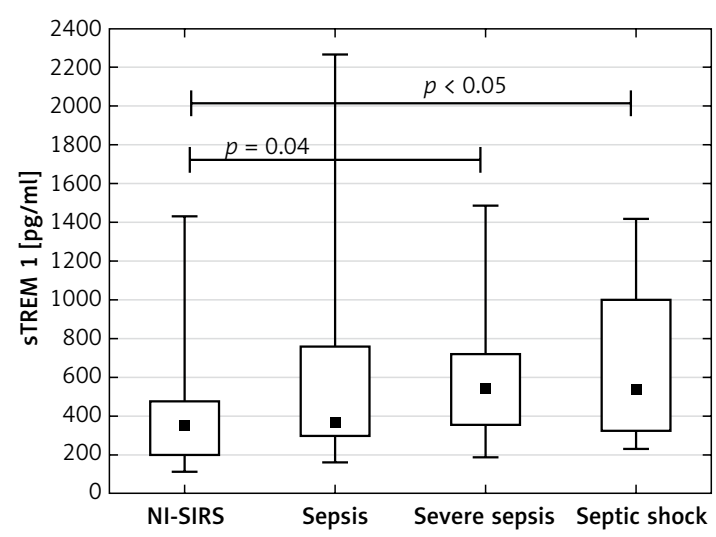

Figure 1. Soluble triggering receptor expressed on myeloid cells-1 (sTREM-1) serum levels on admission day in non-infective SIRS (NI-SIRS), sepsis, severe sepsis and septic shock

The medians, interquartile ranges, min.-max. and $p$-values are shown.

$(p=0.04)$ and in septic shock to $536 \mathrm{pg} / \mathrm{ml}$ $(p<0.05)$ in comparison with NI-SIRS. (Figure 1). Similarly, the difference in serum CRP level between NI-SIRS (46.6 $\mathrm{mg} / \mathrm{l})$ and sepsis $(84 \mathrm{mg} / \mathrm{l})$ was not statistically significant $(p=0.68)$. However, in NI-SIRS and sepsis median CRP levels were significantly lower than in severe sepsis $(163 \mathrm{mg} / \mathrm{l})$ and septic shock $(180 \mathrm{mg} / \mathrm{l})$ patients (Figure 2).

The PCT achieved a median concentration of $1.47 \mathrm{ng} / \mathrm{ml}$ in NI-SIRS, $0.98 \mathrm{ng} / \mathrm{ml}$ in sepsis and $2.11 \mathrm{ng} / \mathrm{ml}$ in severe sepsis, but the differences were not statistically significant $(p=0.36, p=0.19$, respectively). An increased median level of PCT of $7.8 \mathrm{ng} / \mathrm{ml}$ was found in septic shock and it was significantly higher than observed in NI-SIRS, sepsis and severe sepsis (Figure 3). The level of IL-6 did not differ between NI-SIRS $(25.6 \mathrm{pg} / \mathrm{ml})$ and sepsis (97 $\mathrm{pg} / \mathrm{ml}, p=0.68$ ), but was elevated in severe sepsis $(298 \mathrm{pg} / \mathrm{ml})$ and in septic shock (319 pg/ $\mathrm{ml}$ ) in comparison to NI-SIRS and sepsis (Figure 4).

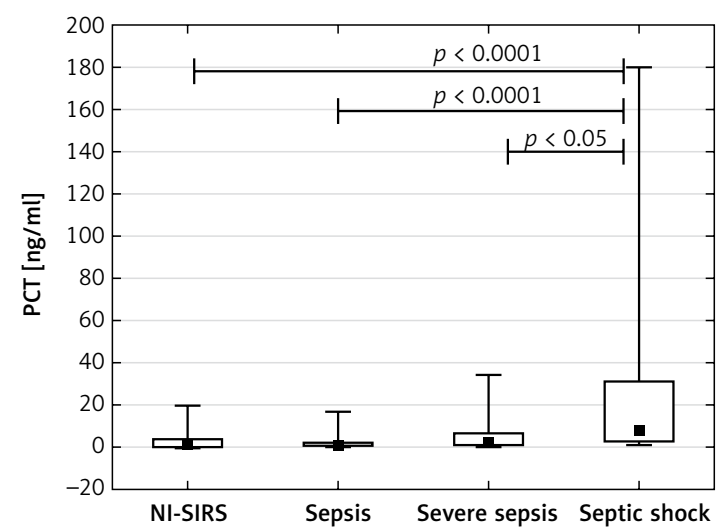

Figure 3. Procalcitonin (PCT) serum levels on admission day in non-infective SIRS (NI-SIRS), sepsis, severe sepsis and septic shock

The medians, interquartile ranges, min.-max. and $p$-values are shown.

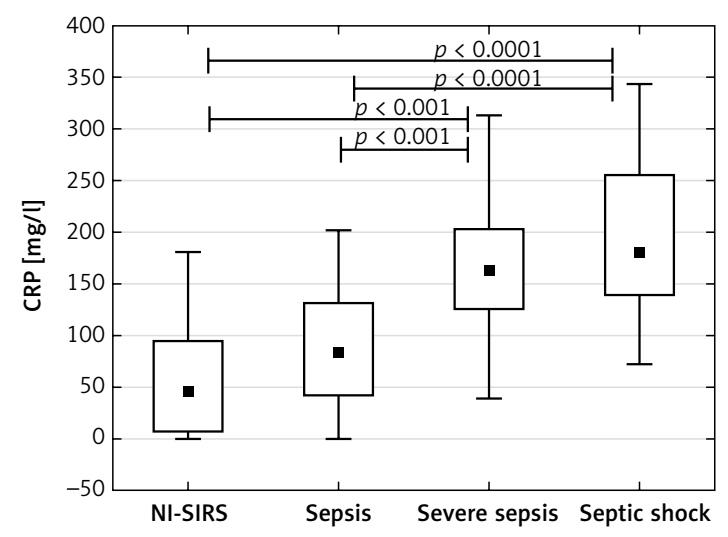

Figure 2. C-reactive protein (CRP) serum levels on admission day in non-infective SIRS (NI-SIRS), sepsis, severe sepsis and septic shock

The medians, interquartile ranges, min.-max. and p-values are shown.

\section{STREM-1, CRP, PCT and IL-6 in diagnosis of systemic infection.}

The highest discriminative value in diagnosis of SI was observed for CRP with a ROC AUC of 0.839 (95\% CI: 0.753-0.924), followed by IL-6, STREM-1 and PCT (Figure 5). The cut-off points which represented the best discrimination, calculated sensitivity, specificity and predictive values are presented in Table II.

\section{sTREM-1, CRP, PCT and IL-6 in diagnosis} of sepsis, severe sepsis or septic shock

We observed no statistically significant differences for AUCS of sTREM-1, CRP, PCT or IL- 6 in the diagnosis of sepsis against NI-SIRS. In severe sepsis CRP had the highest discriminative value with an AUC of 0.909 (95\% Cl: 0.829-0.99), followed by IL-6 (AUC = $0.854,95 \% \mathrm{Cl}: 0.728-0.980$ ), sTREM-1 (AUC $=0.733$, 95\% Cl: $0.596-0.870)$ and PCT (AUC $=0.651,95 \% \mathrm{Cl}$ : 0.502-0.804) (Figure 6). The best cut-off values, sensitivities and specificities are shown in Table III.

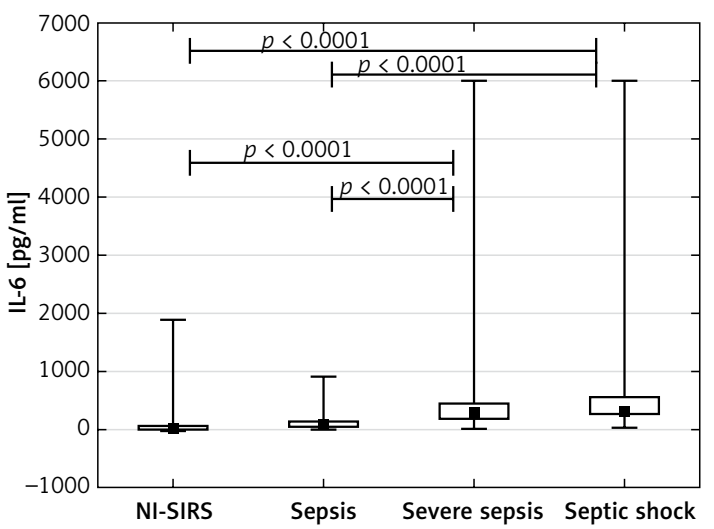

Figure 4. Interleukin-6 (IL-6) serum levels on admission day in non-infective SIRS (NI-SIRS), sepsis, severe sepsis and septic shock

The medians, interquartile ranges, min.-max. and p-values are shown 


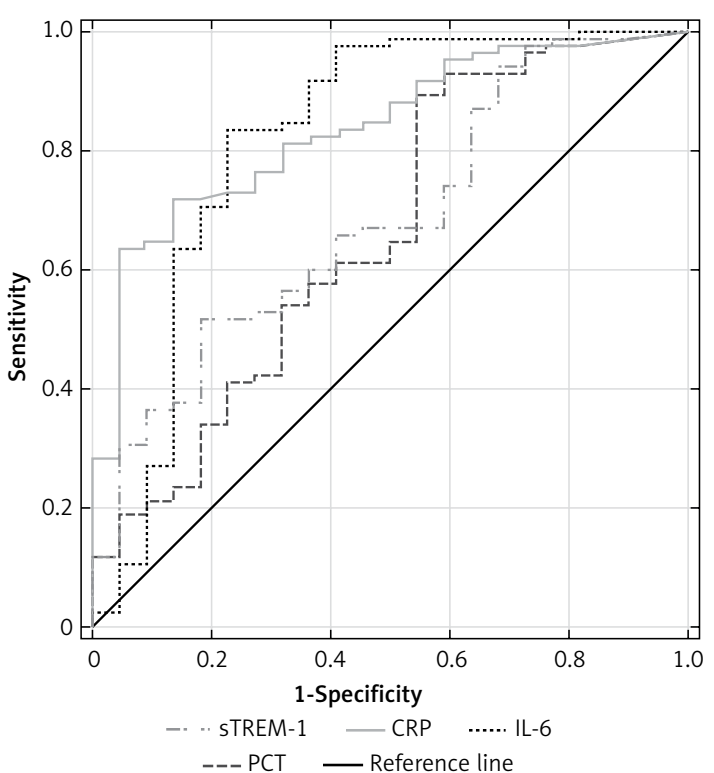

Figure 5. Receiver operating characteristic curves for soluble triggering receptor expressed on myeloid cells-1 (STREM-1), C-reactive protein (CRP), procalcitonin (PCT) and interleukin-6 (IL-6) levels in differentiating between systemic infection and non-infected SIRS

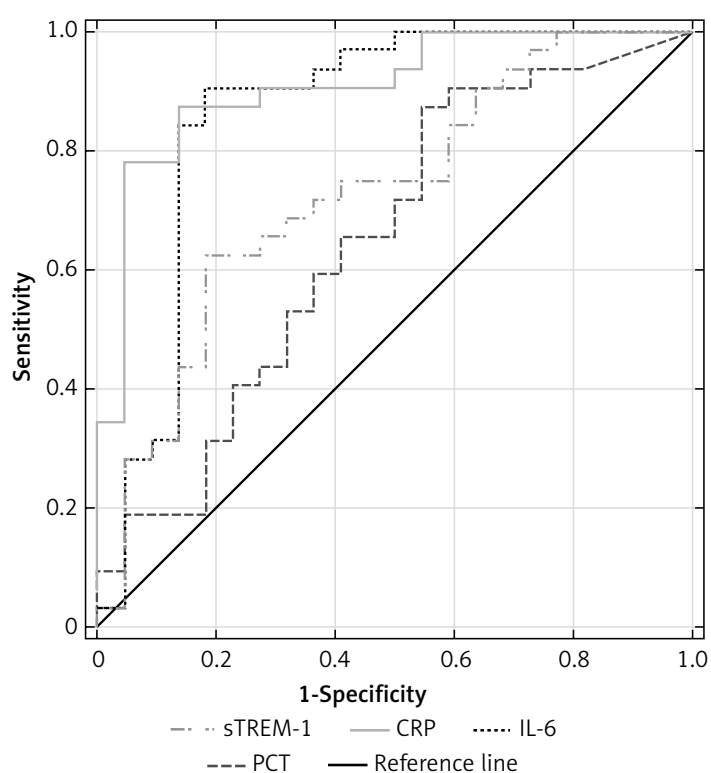

Figure 6. Receiver operating characteristic curves for soluble triggering receptor expressed on myeloid cells-1 (sTREM-1), C-reactive protein (CRP), procalcitonin (PCT) and interleukin-6 (IL-6) levels in differentiating between severe sepsis and non-infective SIRS

Table II. Inflammatory markers in the diagnosis of systemic infection versus non-infective SIRS

\begin{tabular}{|lcccc|}
\hline Parameter & $\begin{array}{c}\text { sTREM-1 } \\
{[\mathrm{pg} / \mathrm{ml}]}\end{array}$ & $\begin{array}{c}\text { C-reactive protein } \\
{[\mathrm{mg} / \mathrm{l}]}\end{array}$ & $\begin{array}{c}\text { Procalcitonin } \\
{[\mathrm{ng} / \mathrm{ml}]}\end{array}$ & $\begin{array}{c}\text { Interleukin-6 } \\
{[\mathrm{pg} / \mathrm{ml}]}\end{array}$ \\
\hline Cut-off value & 229 & 103 & 0.58 & 81.4 \\
\hline Sensitivity (\%) & 94 & 72 & 89 & 84 \\
\hline Specificity (\%) & 32 & 86 & 46 & 77 \\
\hline PPV (\%) & 84 & 95 & 86 & 93 \\
\hline NPV (\%) & 58 & 44 & 53 & 55 \\
\hline AUC (95\% Cl) & 0.681 & 0.839 & 0.659 & 0.820 \\
& $(0.560-0.806)$ & $(0.753-0.924)$ & $(0.522-0.796)$ & $(0.695-0.946)$ \\
\hline Accuracy (\%) & 81 & 75 & 80 & 82 \\
\hline
\end{tabular}

SIRS - systemic inflammatory response syndrome, sTREM-1 - soluble triggering receptor expressed on myeloid cells-1, PPV - positive predictive value, NPV - negative predictive value, AUC - area under curve, $\mathrm{Cl}$ - confidence interval.

Table III. Inflammatory markers in the diagnosis of severe sepsis and septic shock versus non-infective SIRS

\begin{tabular}{|lcccccccc|}
\hline Parameter & \multicolumn{2}{c}{$\begin{array}{c}\text { STREM-1 } \\
{[\mathrm{pg} / \mathrm{ml}]}\end{array}$} & \multicolumn{2}{c}{$\begin{array}{c}\text { C-reactive protein } \\
{[\mathrm{mg} / \mathrm{l}]}\end{array}$} & \multicolumn{2}{c|}{$\begin{array}{c}\text { Procalcitonin } \\
{[\mathrm{ng} / \mathrm{ml}]}\end{array}$} & \multicolumn{2}{c|}{$\begin{array}{c}\text { Interleukin-6 } \\
\text { [pg/ml] }\end{array}$} \\
\cline { 2 - 10 } & $\begin{array}{c}\text { Severe } \\
\text { sepsis }\end{array}$ & $\begin{array}{c}\text { Septic } \\
\text { shock }\end{array}$ & $\begin{array}{c}\text { Severe } \\
\text { sepsis }\end{array}$ & $\begin{array}{c}\text { Septic } \\
\text { shock }\end{array}$ & $\begin{array}{c}\text { Severe } \\
\text { sepsis }\end{array}$ & $\begin{array}{c}\text { Septic } \\
\text { shock }\end{array}$ & $\begin{array}{c}\text { Severe } \\
\text { sepsis }\end{array}$ & $\begin{array}{c}\text { Septic } \\
\text { shock }\end{array}$ \\
\hline Cut-off value & 495 & 363.1 & 103 & 103 & 0.58 & 1.87 & 133.4 & 164 \\
\hline Sensitivity (\%) & 63 & 71 & 88 & 88 & 88 & 88 & 91 & 88 \\
\hline Specificity (\%) & 82 & 59 & 86 & 86 & 46 & 64 & 82 & 86 \\
\hline PPV (\%) & 83 & 65 & 90 & 88 & 70 & 72 & 88 & 86 \\
\hline NPV (\%) & 60 & 65 & 83 & 86 & 71 & 82 & 86 & 86 \\
\hline AUC (95\% Cl) & 0.733 & 0.705 & 0.909 & 0.938 & 0.651 & 0.828 & 0.854 & 0.869 \\
& $(0.596-$ & $(0.553-$ & $(0.829-$ & $(0.872-$ & $(0.502-$ & $(0.71-$ & $(0.728-$ & $(0.751-$ \\
& $0.870)$ & $0.856)$ & $0.99)$ & $1.0)$ & $0.804)$ & $0.945)$ & $0.980)$ & $0.987)$ \\
\hline Accuracy (\%) & 70 & 65 & 87 & 87 & 70 & 76 & 87 & 87 \\
\hline
\end{tabular}

SIRS - systemic inflammatory response syndrome, sTREM-1 - soluble triggering receptor expressed on myeloid cells-1, PPV - positive predictive value, NPV - negative predictive value, AUC - area under curve, $\mathrm{Cl}$-confidence interval. 


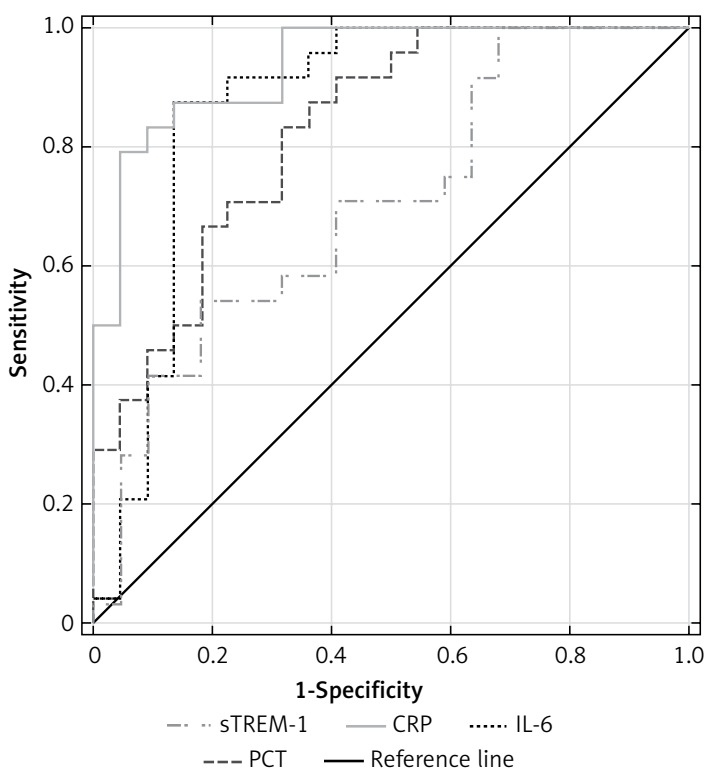

Figure 7. Receiver operating characteristic curves for soluble triggering receptor expressed on myeloid cells-1 (sTREM-1), C-reactive protein (CRP), procalcitonin (PCT) and interleukin-6 (IL-6) levels in differentiating between septic shock and non-infective SIRS

ROCs were also used to calculate serum s-TREM-1, CRP, PCT and IL-6 performance in differentiation between septic shock and NI-SIRS (Figure 7). The highest AUC value was $0.94(95 \% \mathrm{Cl}$ : 0.872-1.0) for CRP with the same cut-off point, sensitivity and specificity as in severe sepsis. Lower AUC values were observed for other mediators (Table III). IL-6, with a cut-off point of $164 \mathrm{pg} / \mathrm{ml}$, achieved sensitivity of $88 \%$ and specificity of $86 \%$, which is identical as for CRP. High sensitivity of $88 \%$ with lower specificity of $64 \%$ was found for PCT, but with a higher cut-off point of $1.87 \mathrm{ng} / \mathrm{ml}$ in comparison with severe sepsis. The lowest sensitivity and specificity with accuracy of $65 \%$ in diagnosis of septic shock were observed for STREM-1.

Combining severe sepsis and septic shock patients into one group, we found similar ROCs for IL- 6 and CRP with AUC of 0.86 (95\% Cl: $0.741-$ 0.98 ) and 0.92 (95\% Cl: 0.856-0.986), respectively, and similar ROCs for PCT and STREM-1, with lower AUC of 0.726 (95\% Cl: $0.599-0.854)$ and 0.721 (95\% Cl: 0.594-0.847) ( $p<0.05)$, respectively, for discriminating against NI-SIRS (Figure 8).

Table IV. Multivariate logistic regression model for patients with severe sepsis and septic shock versus non-infective SIRS

\begin{tabular}{|lccc|}
\hline Parameter & Odds ratio & $95 \% \mathrm{Cl}$ & $P$-value \\
\hline STREM-1 & 1.003 & $1.000-1.005$ & $<0.05$ \\
\hline CRP & 1.037 & $1.018-1.057$ & $<0.001$ \\
\hline
\end{tabular}

STREM-1 - soluble triggering receptor expressed on myeloid cells-1, $C R P-C$-reactive protein, $\mathrm{Cl}$ - confidence interval.

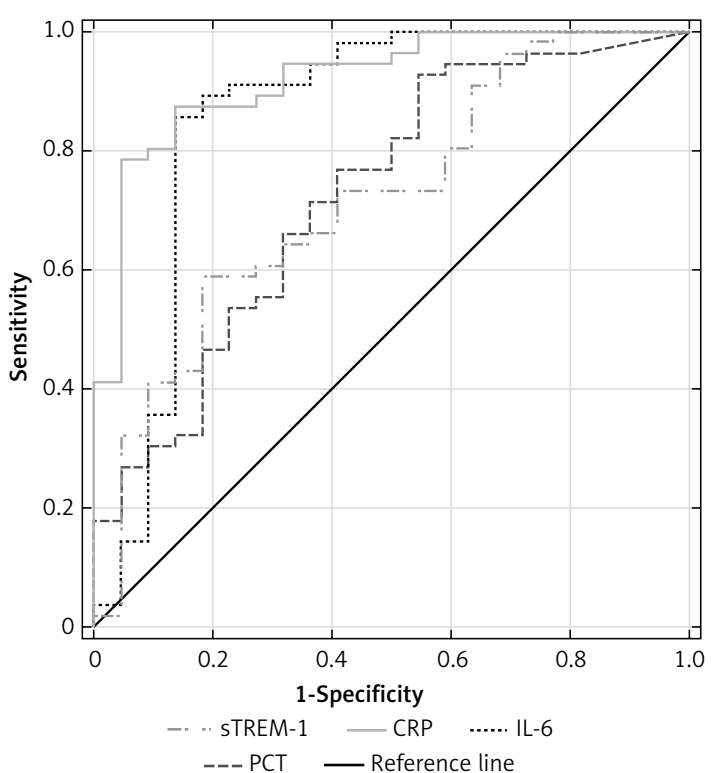

Figure 8. Receiver operating characteristic curves for soluble triggering receptor expressed on myeloid cells-1 (sTREM-1), C-reactive protein (CRP), procalcitonin (PCT) and interleukin-6 (IL-6) levels in differentiating between severe sepsis/septic shock and non-infective SIRS

Looking for an artificial scoring system for sepsis diagnosis, we found the highest effectiveness of the combination of CRP and STREM-1, but only for patients with severe sepsis and septic shock (Table IV). Multivariate logistic regression analysis of the group including sepsis, severe sepsis and septic shock patients showed no improvement in diagnosis using two or more of the studied mediators in comparison to the single one.

\section{Discussion}

In the present study, we observed an early inflammatory response in the course of infective and non-infective SIRS with similar intensity in NI-SIRS and septic patients, but with significantly more intensive inflammation in patients with severe sepsis and septic shock. Detailed analysis has shown that STREM-1, CRP, PCT and IL- 6 cannot discriminate between sepsis and non-infective SIRS in the early stage, but they can be helpful in the diagnosis of severe sepsis and septic shock.

Usefulness of STREM-1 in diagnosis of sepsis has been reported frequently over recent years [14-16]. Gibot et al. [14] observed 96\% sensitivity and $89 \%$ specificity for sTREM-1 in ICU patients with infective SIRS. Likewise, Su et al. [10] analyzed $30 \mathrm{NI}$-SIRS cases and 100 patients with sepsis, severe sepsis and septic shock (together referred to as "sepsis"). They found STREM-1 as an early and strong indicator of sepsis with an AUC of 0.978 (95\% Cl: $0.958-0.997), 91 \%$ sensitivity and $89.6 \%$ specificity for $64.4 \mathrm{pg} / \mathrm{ml}$ as the cutoff point. In the present study we observed AUC 
for STREM-1 of 0.681 (95\% Cl: $0.560-0.806)$, $94 \%$ sensitivity and $32 \%$ specificity with the cut-off point set at $229 \mathrm{pg} / \mathrm{ml}$ in the SI group. The discrepancy in characteristics of NI-SIRS groups may be the reason for observed differences, since Su et al. [10] included patients with median APACHE II of 11 , SOFA of 0 and a mortality rate of $5 \%$, and our NI-SIRS patients' median APACHE II was 13, SOFA was 7.5, SAPS II was 36 points and the mortality rate was $22.7 \%$. In Barati et al.' [17] analysis of 52 septic and 43 NI-SIRS patients, sTREM-1 yielded an AUC of 0.65 (95\% Cl: 0.53-0.76) with $70 \%$ sensitivity and $60 \%$ specificity. The authors confirmed our results, finding better predictive value of CRP than STREM-1 for discrimination between SI and NI-SIRS. Likewise, Kofoed et al. [18] found limited value of STREM-1 as single marker, whereas PCT and CRP exhibited acceptable diagnostic characteristics. In the present study lower AUCS and specificities of STREM-1 in comparison with CRP were also observed in severe sepsis and septic shock in comparison with CRP. Although some authors suggested the high diagnostic value of STREM-1 in sepsis, increased levels of this biomarker were also documented in non-infective severe clinical conditions [19, 20]. Based on the present data, sTREM-1 was found to be more a mediator of inflammation than of infection, as there was no difference in biomarker level between NI-SIRS and sepsis. This was explained by Murakami et al. [21], who demonstrated that $\mathrm{PGE}_{2}$ can induce TREM-1 expression by monocytes and macrophages. Concomitantly, the severity of bacterial infection was shown to be reflected by the mRNA expression levels of TREM-1 in circulating PMNs, and this expression was downregulated during severe sepsis and septic shock [22].

The CRP, PCT and IL- 6 are useful as markers of inflammatory and infectious diseases worldwide. Looking for the best mediator for discrimination between NI-SIRS and SI, we found CRP with an AUC of 0.839 (95\% Cl: $0.753-0.924), 72 \%$ sensitivity and $86 \%$ specificity. Likewise, IL- 6 was also a good discriminating mediator with similar AUC, $84 \%$ sensitivity and $77 \%$ specificity (Table II). Although we found the lowest AUC for PCT in SI diagnosis, the sensitivity of $89 \%$ was even higher than that for IL-6. Lower discriminative values for CRP and IL-6 were presented by Harbarth et al. [11]. They found an AUC of 0.76 (95\% Cl: 0.58-0.93) for CRP with $68 \%$ sensitivity and $73 \%$ specificity at a cut-off point set at $150 \mathrm{mg} / \mathrm{l}$ and an AUC of 0.75 (95\% Cl: $0.63-0.87$ ) for IL-6 with $67 \%$ sensitivity and $72 \%$ specificity at a cut-off point set at $200 \mathrm{ng} /$ $\mathrm{ml}$. Contrary to our results they found good discriminative value for PCT, with an AUC of 0.92 (95\% Cl: $0.85-1.0)$ and $97 \%$ sensitivity and $78 \%$ specificity. Patients' characteristics in Harbarth's study were similar to ours, since the SAPS II score and mortality had similar ranges, but there were 18 NI-SIRS cases and 60 patients with infection, including 14 sepsis cases only. Similarly, Su et al. [10] found high discriminative value of PCT with AUC of 0.806 (95\% Cl: $0.7-0.913), 82 \%$ sensitivity and $75 \%$ specificity with $0.83 \mathrm{ng} / \mathrm{ml}$ as a cut-off point. However, the difference in the characteristics of the NI-SIRS group between our and their study should be noted.

Good diagnostic accuracies of CRP and IL- 6 in detecting systemic infection were confirmed by several studies [10, 17, 18]. However, elevated IL-6 concentrations were also associated with poor outcome in other diseases such as cardiogenic or hemorrhagic shock [23, 24]. Gaïni et al. [25] compared NI-SIRS patients with sepsis or severe sepsis/septic shock and found that CRP and IL-6 are superior to PCT in the diagnosis of infection. Similarly to our results, AUCS for CRP and IL- 6 were over 0.82, while the AUC for PCT was $0.75(95 \% \mathrm{Cl}$ : $0.63-0.87)$.

To find some explanations for the present results we analyzed separately sepsis, severe sepsis and septic shock. Although levels of sTREM-1, CRP, PCT and IL- 6 were significantly higher in severe sepsis and septic shock than in NI-SIRS, there were no significant differences in these mediators' levels between NI-SIRS and sepsis. For severe sepsis no significant elevation of PCT and STREM-1 was found in comparison with sepsis, but CRP and IL-6 increased significantly, suggesting a more intense inflammatory response probably due to an organ origin. IL-6, STREM-1 and CRP concentrations remained high in septic shock and did not differ between severe sepsis and septic shock. In contrast, PCT level was significantly higher in septic shock in comparison with severe sepsis. Diagnostic accuracies of STREM-1, CRP, PCT and IL- 6 were higher when they were analyzed in severe sepsis or septic shock patients separately in comparison to the results for the SI group (Tables II, III). For STREM-1, CRP and IL-6, AUC values were similar in severe sepsis and septic shock. PCT behaved in a different way, as AUC increased from 0.65 (95\% Cl: $0.502-0.804)$ in severe sepsis to 0.83 (95\% Cl: 0.71-0.945) in septic shock.

Several limitations of this study merit consideration. First, clinical criteria and microbiological results were used to establish the diagnosis. Thus it was difficult to define precisely the exact cause of SIRS in all patients. This may result in some misclassification regardless of the fact that investigators were blinded to STREM-1 results. Second, our sample size limits the usefulness of the results in making decisions in clinical settings. Third, clinical care before admission to the ICU can influence the internal environment and mediators' levels. Similarly, different origins of infection in studied cases may be associated with poor outcome of STREM-1. 
However, making any conclusion needs a separate and detailed analysis with a larger sample size.

In conclusion, according to our observations, infective and non-infective SIRS results in systemic elevation of STREM-1, CRP, PCT and IL-6 levels. Although the provisional analysis suggested stronger intensity of inflammation in patients with infection in comparison with NI-SIRS, detailed scrutiny showed that the difference concerned severe sepsis and septic shock, and not sepsis without complications. Serum level of STREM-1 allows for the differentiation between severe sepsis or septic shock and NI-SIRS, but CRP and IL- 6 showed higher diagnostic accuracy in these conditions. The effectiveness of STREM-1 in the diagnosis of severe sepsis is similar to that seen in septic shock. We confirmed that diagnostic mediators should be used in close relation to the disease severity.

Thus, we suggest that STREM-1 is a mediator of inflammation and not infection per se. The influence of additional factors such as organ dysfunction and shock on the circulatory level of STREM-1 needs further evaluation.

\section{Acknowledgments}

This study was supported by Polish National Science Centre (Grant number N N403 571638). We wish to thank all of the doctors and nurses in the Department of Anesthesiology and Intensive Care of Medical University of Bialystok for their support and assistance.

\section{Conflict of interest}

The authors declare no conflict of interest.

\section{References}

1. Vincent JL, Sakr Y, Sprung CL, et al. Sepsis occurrence in acutely ill patients investigators: sepsis in European intensive care units: results of the SOAP Study. Crit Care Med 2006; 34: 344-53.

2. Tomasiuk R, Mikaszewska-Sokolewicz M, Szlufik S, Rzepecki P, Lazowski T. The prognostic value of concomitant assessment of NT-proCNP, C-reactive protein, procalcitonin and inflammatory cytokines in septic patients. Crit Care 2014; 18: 440.

3. Pelham CJ, Pandya AN, Agrawal DK. Triggering receptor expressed on myeloid cells receptor family modulators: a patent review. Expert Opin Ther Pat 2014; 24: 1383-95.

4. Bouchon A, Facchetti F, Weigand MA, Colonna M. TREM-1 amplifies inflammation and is a crucial mediator of septic shock. Nature 2001; 410: 1103-7.

5. Giamarellos-Bourboulis EJ, Zakynthinos S, Baziaka F, et al. Soluble triggering receptor expressed on myeloid cells 1 as an anti-inflammatory mediator in sepsis. Intensive Care Med 2006; 32: 237-43.

6. Gibot S, Cravoisy A. Soluble form of the triggering receptor expressed on myeloid cells- 1 as a marker of microbial infection. Clin Med Res 2004; 2: 181-7.
7. Jiyong J, Tiancha H, Wei C, Huahao S. Diagnostic value of the soluble triggering receptor expressed on myeloid cells-1 in bacterial infection: a meta-analysis. Intensive Care Med 2009; 35: 587-95.

8. Oudhuis GJ, Beuving J, Bergmans D, et al. Soluble triggering receptor expressed on myeloid cells-1 in bronchoalveolar lavage fluid is not predictive for ventilator-associated pneumonia. Intensive Care Med 2009; 35: 1265-70.

9. Determann RM, Weisfelt M, de Gans J, Van der Ende A, Schultz MJ, van de Beek D. Soluble triggering receptor expressed on myeloid cells 1: a biomarker for bacterial meningitis. Intensive Care Med 2006; 32: 1243-7.

10. Su L, Feng L, Song Q, et al. Diagnostic value of dynamics serum SCD163, sTREM-1, PCT, and CRP in differentiating sepsis, severity assessment, and prognostic prediction. Mediators inflamm 2013; 2013: 969875.

11. Harbarth S, Holeckova K, Froidevaux C, et al. Diagnostic value of procalcitonin, interleukin-6, and interleukin-8 in critically ill patients admitted with suspected sepsis. Am J Respir Crit Care Med 2001; 164: 396-402.

12. Dellinger RP, Levy MM, Carlet JM, et al. Surviving sepsis campaign: international guidelines for management of severe sepsis and septic shock: 2008. Intensive Care Med 2008; 34: 17-60.

13. Levy MM, Fink MP, Marshall JC, et al. 2001 SCCM/ESICM/ACCP/ATS/SIS International Sepsis Definitions Conference. Crit Care Med 2003; 31: 1250-6.

14. Gibot S, Kolopp-Sarda MN, Bene MC, et al. Plasma level of triggering receptor expressed on myeloid cells-1: its diagnostic accuracy in patients with suspected sepsis. Ann Intern Med 2004; 141: 9-15.

15. Gibot S, Cravoisy A, Levy B, Bene MC, Faure GC, Bollaert PE. Soluble triggering receptor expressed on myeloid cells and the diagnosis of pneumonia. N Engl J Med 2004; 350: 451-8.

16. Richeldi L, Mariani M, Losi M, et al. Triggering receptor expressed on myeloid cells: role in the diagnosis of lung infections. Eur Respir J 2004; 24: 247-50.

17. Barati M, Bashar FR, Shahrami R, et al. Soluble triggering receptor expressed on myeloid cells 1 and diagnosis of sepsis. J Crit Care 2010; 25: 362. e1-6.

18. Kofoed K, Andersen O, Kronborg G, et al. Use of plasma C-reactive protein, procalcitonin, neutrophils, macrophage migration inhibitory factor, soluble urokinase-type plasminogen activator receptor, and soluble triggering receptor expressed on myeloid cells-1 in combination to diagnose infections: a prospective study. Crit Care 2007; 11: R38.

19. Phua J, Koay ES, Zhang DH, et al. Soluble triggering receptor expressed on myeloid cells- 1 in acute respiratory infections. Eur Respir J 2006; 28: 695-702.

20. Tzivras M, Koussoulas V, Giamarellos-Bourboulis EJ, et al. Role of soluble triggering receptor expressed on myeloid cells in inflammatory bowel disease. World J Gastroenterol 2006; 12: 3416-9.

21. Murakami Y, Kohsaka H, Kitasato H, Akahoshi T. Lipopolysaccharide-induced up-regulation of triggering receptor expressed on myeloid cells- 1 expression on macrophages is regulated by endogenous prostaglandin E2. J Immunol 2007; 178: 1144-50.

22. Ubagai T, Nakano R, Kikuchi H, Ono Y. Gene expression analysis of TREM1 and GRK2 in polymorphonuclear leukocytes as the surrogate biomarkers of acute bacterial infections. Int J Med Sci 2014; 11: 215-21.

23. Debrunner M, Schuiki E, Minder E, et al. Proinflammatory cytokines in acute myocardial infarction with and 
without cardiogenic shock. Clin Res Cardiol 2008; 97:

298-305.

24. Villarroel JPP, Guan Y, Werlin E, Selak MA, Becker LB,

Sims C. Hemorrhagic shock and resuscitation are associated with peripheral blood mononuclear cell mitochondrial dysfunction and immunosuppression. J Trauma Acute Care Surg 2013; 75: 24-31.

25. Gaïni S, Koldkjær OG, Pedersen C, Pedersen SS. Procalcitonin, lipopolysaccharide-binding protein, interleukin-6 and C-reactive protein in community-acquired infections and sepsis: a prospective study. Crit Care 2006; 10: R53. 